\title{
Francesc Eiximenis y Luis Vives: la clave de la verdad
}

\author{
FRANCISCO CALERO
}

(UNED)

0.- En el año 2003 defendí que el insigne valenciano Luis Vives escribió varias de las obras más importantes de la literatura española, entre las que se encuentran Diálogo de la lengua y Lazarillo de Tormes. A partir de entonces en tres libros y bastantes artículos he demostrado por activa y por pasiva que los hechos eran tal como los había expuesto en mi trabajo inicial. Tal vez me faltaba demostrarlo por perifrástica (seguramente para hacer honor a mis estudios latinos), y es lo que voy a hacer ahora. En otras palabras, quiero ofrecer la prueba del nueve, como se suele decir cuando algo es incontrovertible.

La clave de la verdad se encuentra en un libro extraordinariamente complejo, que merece un estudio de centenares de páginas. Por ahora me detendré sólo en los puntos esenciales para llevar a cabo la demostración de mis tesis. Dicho libro ha suscitado el interés de los investigadores desde los inicios del siglo xx. Citaré en esa línea de investigación los trabajos de Julia FitzmauriceKelly «Vives and the Carro de las donas», de Juan Meseguer Fernández «El traductor del Carro de las donas, de Francisco Eximenez, familiar y biógrafo de Adriano VI», de David Viera «Más sobre Vives y el Carro de las donas», del mismo David Viera «Un estudio textual del Carro de las donas, adaptación del Llibre de les dones», de Isaac Vázquez Janeiro «En busca de un nombre para el traductor del Carro de las donas de F. Eximenez», y especialmente la excelente tesis de Carmen Clausell Nácher Carro de las donas. Valladolid, 1542. Adaptación del Llibre de les dones de Francesc Eiximenis O.F.M. realizada por el P. Carmona O.F.M. Por los trabajos citados fácilmente puede deducirse que se trata de una problemática difícil, que trataré de exponer de la forma más sencilla posible.

0.1.- En el año 1495 fue publicado en Barcelona el Libre de les dones del franciscano Francesc Eiximenis. Es doctrina común que esta obra influyó en Luis Vives, al componer su De institutione feminae christianae, publicada en Amberes en 1524. De la obra de Vives se hicieron dos traducciones al castellano: la primera, realizada por Juan Justiniano, fue publicada en Valencia el año 1528; la segunda, anónima, vio la luz en Alcalá de Henares en 1529. 
0.2.- En el año 1542 apareció en Valladolid el libro que estudiamos bajo el título: Este deuoto libro se llama carro de las donas, trata de la vida y muerte del hombre christiano. En apariencia se trata solamente de la traducción del Libre de les dones, pero, como suele ocurrir en muchos libros, encierra mucho más de lo que aparece en la portada. Además de dicha traducción, el enigmático traductor puso mucho de su cosecha. Así en el libro I añadió dos interesantísimas biografías: la del papa Adriano VI y la del primer arzobispo de Granada Fray Hernando de Talavera, así como otras de personajes importantes de finales del siglo XV y principios del XVI. En el libro II añadió la biografía de Isabel la Católica y la de sus hijas. En el libro III añadió las biografías de dos ilustres mujeres: Teresa de Quiñones, esposa del almirante de Castilla, y Teresa Enríquez, esposa del comendador mayor Gutierre de Cárdenas. Especialmente significativas son las adiciones tomadas de De institutione feminae christianae de Vives. Finalmente, el libro V, dedicado a la preparación para la muerte, es original del traductor.

0.3.- El primero que llamó la atención sobre tan complejo libro fue el gran hispanista R. Foulché-Delbosc, quien en 1926 escribió una carta a J. Fitzmaurice-Kelly, en la que le decía ${ }^{1}$ : «Este traductor de Eximeniç merece ser ahorcado ¿no es así? o incluso ser quemado a fuego lento. ¡Qué quiere Vd.! 'Hay honradez o no la hay'». Tremendas palabras contra el traductor, porque constataba que allí había párrafos enteros tomados de Vives.

0.4.- Como consecuencia de la carta de Foulché-Delbosc, J. Fitzmaurice-Kelly hizo la comparación textual correspondiente, poniendo en una columna el texto original de Vives, tomado de la edición príncipe, y en la otra el texto que aparece en la traducción de 1542. Y con esa demostración se dio por satisfecha la investigadora inglesa.

0.5.- Los pasos siguientes fueron dados por J. Meseguer Fernández, D. Viera e I. Vázquez Janeiro en los trabajos ya citados. Las diversas propuestas sobre la autoría del adaptador del Carro de las donas han sido rebatidas por C. Clausell, por lo que me detendré solamente en la suya. Tengo que hacer una objeción inicial a su tesis y es la siguiente: si en la adaptación del Carro de las donas hay numerosos textos de Vives, ¿cómo no se plantea al menos la posibilidad de que detrás del anonimato se ocultara el propio Vives? Por lo que se refiere a su propuesta de autoría, el P. Carmona, hay que señalar que está basada en un solo argumento, que es además ajeno al texto del Carro. Quiero decir que en ningún lugar de la obra se afirma que el traductor fuera el confesor de Adriano VI. En efecto, C. Clausell se basa solamente en una sugerencia de J. Meseguer Fernández²: «Quizá como confesor». Del P. Carmona sabemos que fue confesor de Adriano VI, pero no sabemos

\footnotetext{
${ }^{1}$ Fitzmaurice-Kelly, J., «Vives and the Carro de las donas», p. 530.

${ }^{2}$ Meseguer Fernández, J., «El traductor del Carro de las donas...», p. 234.
} 
cuándo murió, si conocía el catalán para hacer la traducción, si escribió algo, cuál era su forma de traducir, etc. Claramente lo dice C. Clausell, siguiendo a E. Boehmer ${ }^{3}$ : «Este erudito alemán dedica atención al confesor de Adriano VI, personalidad que se dibuja con trazos gruesos en boca de Fr. Francisco Ortiz, pero que se escurre misteriosamente en todas las biografías consultadas del Pontífice».

Por razones de método resulta muy difícil resolver la autoría de una obra anónima con un solo argumento, y más si este argumento está basado en algo exterior a la obra. Siempre hay que partir de lo que se expresa en su texto, así como de las características de la lengua y, especialmente, del estilo. En el paso siguiente se han de hacer comparaciones con otros textos del autor que se propone.

Quisiera hacer otra consideración metodológica sobre si se ha de considerar que todo lo que se dice en una obra es conforme a la verdad. Mi respuesta es que no, sobre todo en aquellas obras que encierran misterios, como son las anónimas. Hay que pensar que si el autor no quiso poner su nombre fue por algo y que, por tanto, puede hacer afirmaciones que traten de despistar a los lectores. Por esa razón pienso que las afirmaciones que den base a los argumentos tienen que estar contrastadas con hechos exteriores a la obra que se estudie. Solamente así tendremos la seguridad de que los fundamentos en los que nos apoyamos son sólidos. Además, cuanto más numerosos sean tanto mayor será su valor probatorio, siempre que confluyan en la misma dirección, esto es, que todos se puedan aplicar al autor que se propone y solamente a él.

0.6.- Voy a transcribir un párrafo del primer artículo del P. Meseguer, porque me parece interesante para iniciar la investigación por el camino correcto ${ }^{4}:$ $\ll \mathrm{Si}$ me ha sido fácil probar quién no pudo ser el traductor, no he logrado saber cómo se llamaba. Y es el caso que, si bien ocultó su nombre cuidadosamente, ha consignado bastantes datos autobiográficos que nos revelan una personalidad de cierto relieve. Será útil recogerlos. Con ellos a la vista, otros investigadores más afortunados podrán bautizarle con su verdadero nombre». Sabias palabras las del P. Meseguer, con las que pone de manifiesto que el traductor dejó datos autobiográficos y que fue una personalidad de relieve. Lo que yo he llevado a cabo es recoger esos datos y así poder bautizarlo con su verdadero nombre: Juan Luis Vives. De esta forma paso a la exposición de los argumentos que he descubierto a su favor, teniendo en cuenta que las comparaciones las voy a establecer solamente con las obras latinas de Vives, a fin de que no quepa la más mínima duda sobre su autenticidad.

\section{La dedicatoria}

La dedicatoria del libro de 1542 es de extraordinaria importancia (yo creo que decisiva) para la determinación de la autoría de la traducción. Está dedicado

\footnotetext{
${ }^{3}$ Clausell Nácher, C., Carro de las donas... I, 106.

${ }^{4}$ Meseguer Fernández, J. «El traductor del Carro de las donas...» p. 233.
} 
a D. ${ }^{a}$ Catalina, esposa de Juan III, rey de Portugal. ¿Quién podía atreverse a dedicarles una obra a tales personajes? Con toda seguridad el más indicado era Vives. La demostración la haré con la ayuda de los datos ofrecidos por Valentín Moreno en su exhaustiva obra La recepción hispana de Juan Luis Vives. En el año 1531 Vives dedicó a Juan III su obra magna De disciplinis. De 1534 se conserva una carta de Vives al monarca portugués, en la que le aconseja la creación de universidades en Portugal. De eso se deduce que las relaciones de Vives con los monarcas portugueses fueron de reconocimiento mutuo e incluso de amistad, hasta el punto de que Juan III le hizo valiosos regalos a Vives tras la dedicatoria de De disciplinis. El hecho es muy significativo porque el monarca no respondía a los que le dedicaban sus obras, ni siquiera a Erasmo: «el lovaniense Juan Nys, con su De ecclesiasticis scripturis et dogmatibus (1533) tampoco obtuvo respuesta, al igual que el propio Erasmo en 1527 al ofrecerle las Chrysostomi Lucubrationes». La consecuencia de todas estas circunstancias es clara: si Vives ya le había dedicado una obra, si mantenía con él trato epistolar, al encontrarnos con una dedicatoria anónima a su esposa Catalina, lo lógico es pensar que procedía de Vives, sobre todo porque sabemos que no le agradaban dedicatorias de otros escritores.

\section{La universidad de Coimbra}

Dos veces es mencionada la universidad de Coimbra en el Carro de las donas: en el Prólogo, I, 132, refiriéndose a Juan III, se afirma:

socorro y augmentador de letrados, que, para los augmentar e socorrer, mandó hazer una gran universidad en la ciudad de Coimbra muy bien dotada

y en el libro IV, II, 306, escribiendo sobre el mismo rey:

Y en la misma ciudad, haze su alteza una universidad como la de Salamanca...

Tal insistencia por parte del traductor apunta directamente a Vives, quien en carta al monarca portugués de 18 de septiembre de 1534 había aconsejado la construcción de una o dos universidades, p. 584:

me parece que sería un gran beneficio de tu reino, si fundaras en él una o dos universidades.

De hecho los historiadores portugueses han relacionado la construcción de la universidad de Coimbra con el consejo de Vives, y también el jesuita Eugenio Fernández Almuzara en su artículo «Influencia de España en la restauración de la Universidad de Coimbra. Vives y Juan III».

\footnotetext{
${ }^{5}$ Moreno Gallego, V., La recepción hispana de Juan Luis Vives, p. 160.
} 


\section{Bajo el favor de la reina de Portugal}

Al final del Carro de las donas el adaptador y adicionador escribió una frase muy significativa, II, 686:

Y también doy gracias a vuestra real alteza porque debaxo de sus alas me dio favor y fuerças para acaballo.

De esas palabras se deduce que la reina de Portugal alentó y favoreció la composición de la obra, seguramente con una ayuda económica, dada la difícil situación económica de Vives, esto es, se repetía lo ocurrido con la dedicatoria de De disciplinis en 1531.

\section{La Dedicatoria a Juan Barros}

En confirmación de las estrechísimas relaciones entre Vives y los monarcas portugueses voy a traer a colación la Dedicatoria que hizo Vives de su obra Excitaciones animi in Deum (1535) a Juan Barros, tesorero de Indias del rey de Portugal (Jiménez, pp. 595-596):

Para ello compuse un opúsculo para mi uso particular. Y cuando me pareció bien hacer partícipes de él a muchos, hízome grande y honorífica mención de ti mi amigo Cristóbal Miranda... Mucho me felicito por esos grandes talentos de Portugal; y colijo la prudencia y bondad de su monarca, además de otras muchas pruebas, por el hecho de poner al frente de los cargos públicos a varones semejantes.

\section{Traducir del catalán al castellano}

Si se propusiera otro autor para la traducción, habría que demostrar que conocía el catalán para ser capaz de llevarla a cabo. En el caso de Vives no hay que hacer tal demostración por su origen valenciano. A eso hay que añadir que Eiximenis, nacido en Gerona, había desarrollado su actividad literaria principalmente en Valencia.

\section{La temática}

El argumento del Llibre de les dones era muy querido para Vives, como sabemos por la composición de su De institutione feminae christianae, que recibió la influencia del franciscano. ¿Quién podía estar más interesado que Vives en ofrecer una traducción castellana de la obra catalana? Evidentemente, nadie.

\section{Repartir a los pobres}

En el Carro de las donas hay bastantes referencias a los pobres, entre las que se encuentra la siguiente, II, 352: 
tomando y gastando dellos [los bienes materiales] lo que honestamente según su estado les fuere necessario y huvieren menester, den y repartan con los que necessidad tuvieren y fueren pobres todo lo demás que a sí les sobrare.

La misma idea de repartir entre los pobres lo que sobra tras cubrir las necesidades fue expresada por Vives en De subventione pauperum, p. 114:

finalmente es ladrón quien no reparte a los pobres lo que le sobra de las necesidades naturales.

\section{La biografía del papa Adriano VI}

Llama la atención que en una obra dedicada a las mujeres el traductor incorporara biografías de hombres, especialmente la del papa Adriano VI. Sin ninguna duda, el traductor tenía que conocer la vida del papa y sentir una gran admiración por él. Las dos condiciones se dan en Vives. Es de todos conocido que en su De Europae dissidiis et Republica Vives incluyó una extensa carta a Adriano VI con motivo de su elección como papa. De esa importantísima misiva pondré aquí sólo unas líneas, p. 11:

Ahora por fin, calmado aquel entusiasmo de los espíritus, que suele provocarse con los nuevos cargos y honores, me ha parecido el momento oportuno de escribir unas palabras a Tu Santidad, príncipe ya de los sacerdotes y de la religión cristiana, puesto que te escribí cuando eras deán de Lovaina y obispo de Tortosa...

y en la despedida, p. 25:

sólo me movía mi antiguo y sólido amor hacia ti y el respeto a la majestad y no a la autoridad de tu cargo. En tu mano estará que, mirando por el bien, hagas que no queden defraudados mi exagerado amor ni mi desmesurada piedad...

Con estos dos pasajes la demostración resulta incontrovertible.

\section{La biografía de Isabel la Católica y de sus hijas}

Como ya hemos adelantado entre los añadidos del traductor está la biografía de la Reina Católica y de sus hijas. A nadie extrañará que este añadido proceda de Vives, porque ya en su De institutione feminae christianae las había propuesto como modelos de mujeres. Pondremos dos pasajes para la demostración, p. 49:

La reina Isabel, esposa de Fernando, quiso que sus cuatro hijas aprendieran a hilar, coser y bordar con soltura, dos de las cuales fueron reinas en Portugal, la tercera, que es la madre del rey Carlos, vemos que lo es de España, y la cuarta, esposa honorabilísima del rey Enrique VIII, lo es de Inglaterra... 
y en pp. 61-62:

Nuestra época ha visto a las cuatro hijas de la reina Isabel, instruidas todas ellas y a las que he nombrado un poco antes. Por todos los rincones de estas tierras me cuentan, no sin elogios y muestras de admiración, que Juana, esposa del rey Felipe, madre de nuestro don Carlos, respondía en latín al instante a quienes le hacían preguntas en esa misma lengua, según costumbre entre los nuevos príncipes cuando van de pueblo en pueblo. Lo mismo comentan los británicos de su reina Catalina, hermana de Juana. Todo el mundo traslada los mismos elogios a las otras dos hermanas que murieron en Portugal. En la memoria de los hombres no ha habido mujeres con un pudor más sincero que estas cuatro hermanas, ni con una fama más pura y más intachable; ni han existido jamás otras reinas más complacientes y amables con sus propios pueblos, ni otras esposas que amaren más a sus maridos, ni otras que les obedecieran con mayor sumisión; ningunas otras que, con mayor cuidado, se conservaran a sí mismas y a los suyos más libres de mancha; ningunas a quien disgustara más la torpeza y la lascivia; ningunas que, con mayor precisión y exactitud, reunieran todas las cualidades de una mujer honrada.

En las demostraciones de autoría los argumentos de mayor valor probatorio son los que se basan en pequeños detalles, como es el que encontramos en la biografía de Juana la Loca. En De institutione se refiere Vives a sus conocimientos de latín, p. 61:

respondía en latín al instante a quienes le hacían preguntas en esa misma lengua...

y en el Carro de las donas se alude también a su formación en letras: I, 435:

fue de muy claro ingenio y muy sabia y muy gran letrada...

Nota: ¿Quién mejor que Vives podía escribir sobre Isabel la Católica y sus hijas? Sin ninguna duda él estuvo en las mejores condiciones para hacerlo, ya que en las largas conversaciones que durante cinco años mantuvo con Catalina en el palacio de los reyes de Inglaterra, la hija de Isabel y Fernando le hablaría con frecuencia de su madre y de sus hermanas.

\section{La suerte de Carlos V}

En la Dedicatoria a Carlos V de De concordia et discordia in humano genere resaltó Vives su fortuna, al salir victorioso en situaciones muy adversas, p. 51:

La ventura de tu nacimiento ha quedado comprobada con tantas victorias como se te ofrecieron fuera de toda esperanza.

La misma idea fue expresada en el Carro de las donas, I, 435: 
succedió en su lugar el Emperador nuestro señor su hijo, el qual es tan bien afortunado que, quando las cosas tiene entre manos, paresce que están más al fin, y allí nuestro señor dios las buelve en prosperidad y honra y provecho suyo.

\section{Un hombre enfermo}

El traductor del Carro de las donas era un hombre muy enfermo, ya que nada menos que en cinco pasajes hace referencia a sus enfermedades:

y porque según mis enfermedades me dio las gracias que lo acabasse $(I, 136)$

aunque impedimentos y enfermedades me eran contrarias (I, 138).

porque a la sazón questo se escrivió yo estava enfermo, como por no tener yo bastante memoria como yo quisiera (I, 517).

Porque yo he tenido y tengo muchas enfermedades (II, 469).

E doyle infinitas gracias, que por su bondad me lo dexó acabar, según mis enfermedades y poco aparejo que yo tenía (II, 685).

La identificación del traductor con Vives no puede ser más evidente. En efecto, Vives a lo largo de su epistolario se refiere una y otra vez a sus enfermedades, como queda demostrado en las siguientes cartas:

1. ${ }^{a}$ Preferí demorar el Agustín, a sucumbir en la tarea o quedar inútil para otros trabajos, cargado de enfermedades y sin otro medio de vida (Vives a Erasmo en 1521, p. 226, Jiménez).

2. ${ }^{a}$ El sueño está enojado conmigo y no sé por qué. Si no hace las paces, me temo que deje en mí como secuela alguna dolencia mayor (Vives a Cranevelt en 1522, p. 249, Jiménez).

3. Además estoy un poco enfermo (Vives a Erasmo en 1522, p. 260, Jiménez).

4. ${ }^{a}$ No quiero disputar contigo de temas filosóficos... sobre todo porque, no sé por qué fatalidad, todas nuestras disputas de filosofía se me truecan en enfermedad... Mi salud es más endeble que cuando te escribí la última vez. Paréceme tener magullado todo el cuerpo y diríase que mi cabeza tiene que sostener un peso insoportable (Vives a Cranevelt en 1522 , pp. 262 y 264 , Jiménez).

5. Así que, lo que antes nunca me sucedió, ahora padezco con frecuencia de molestias de estómago y siento retortijones de vientre, enfermedad no nueva de cuando estaba en Flandes, pero aquí familiar y diaria (Vives a Cranevelt en 1523, pp. 326-327, Jiménez). 
6. ${ }^{\mathrm{a}}$ y también porque no estoy muy bien de la cabeza (Vives a Cranevelt en 1525, p. 402, Jiménez).

7. ${ }^{a}$ También a mí, una nueva dolencia y muy diversa de la del día anterior (Vives a Héctor Decamio en 1525, p. 403, Jiménez).

$8 .^{a}$ cuando me encuentre mejor del vientre, que ayer me hizo pasar todo el día muy agudos dolores (Vives a Cranevelt en 1527, p. 487, Jiménez).

9. ${ }^{a}$ puesto que no puedo prestar remedio a tantos males por la flaqueza de mis fuerzas (Vives a Budé en 1529, p. 537, Jiménez).

$10{ }^{a}$ Por lo que a mí toca, el mal de gota me atormenta terriblemente; sube serpenteando hasta las rodillas, hasta las manos, hasta los brazos y los hombros (Vives al señor de Praets en 1531, p. 551, Jiménez).

11. ${ }^{\text {a }}$ Por lo que a mí respecta, me impuso este silencio un dolor continuo de cabeza y de ojos que no paró en todo el verano (Vives a P. Maluenda en 1531, p. 568, Jiménez).

12. ${ }^{a}$ El que no haya contestado aún tu carta, mi querido Damián, no obedece a falta de voluntad, que es muy grande para contigo, como has podido observar, sino a mi poca salud, que con enormes dolores ha estado amenazando las fuerzas de mi cuerpo y de mi alma (Vives a Damián Goes en 1533, p. 574, Jiménez).

13. ${ }^{\mathrm{a}}$ Te hago saber que desde hace tres años estoy sufriendo un grave dolor de cabeza y de ojos (Vives a Juan de Vergara en 1532, p. 576, Jiménez).

14. ${ }^{\text {a }}$ El verano pasado me aquejó grave y peligrosamente un cólico. El mal de gota se me ha hecho tan familiar, que me resulta menos molesto por la costumbre (Vives a Erasmo en 1534, p. 580, Jiménez).

15. ${ }^{\text {a }}$ Lo qual yo hiziera de buena gana, según lo requería nuestra amistad, si no me impidieran en parte mis dolencias, y en parte mis ocupaciones (Vives a Diego Ortega en 1536, p. 603, Jiménez).

16. ${ }^{a}$ Efectivamente, la falta de salud me quita mucho tiempo (Vives a Simón Gryneo en 1538, p. 607, Jiménez).

Nota: La mayor preocupación de Vives fue la de su mala salud, como también lo fue la del traductor anónimo.

\section{A las puertas de la muerte}

Este apartado está en íntima conexión con al anterior, ya que de los textos ya citados en él se deduce que el traductor estaba próximo a la muerte. Así se evidencia por el hecho de dar gracias a Dios por haberle permitido terminar la obra. Perdóneseme insistir en ellos:

y porque según mis enfermedades me dio las gracias que lo acabasse... 
E doyle infinitas gracias, que por su bondad me lo dexó acabar, según mis enfermedades...

Si estos textos se escribieron en 1539, es claro que a quien mejor se pueden referir es a Vives, que estaba muy próximo a la muerte, ocurrida el 6 de mayo de 1540.

\section{La forma de traducir}

La traducción del Libre de les dones presenta unas características distintivas que sirven para identificar al traductor. Así una palabra puede ser traducida por dos, se producen eliminaciones de palabras o de frases y se añaden frases e incluso párrafos. La editora Carmen Clausell señala esas discrepancias respecto al original por medio de la letra cursiva. Pondremos sólo una muestra, I, 154:

E assí, por ser la compañía del hombre y de la muger exemplo de tan alto mysterio y sacramento (del qual dize sant Pablo que el sacramento del matrimonio es grande en significación porque significa el ayuntamiento de Christo con la yglesia), e por esta causa, el bien casado y buena casada serán llevados y ensalçados entre los sanctos con mucha gloria y honor...

¿A quién corresponde tal forma de traducir? Con seguridad a Luis Vives, quien la defendió en De ratione dicendi en el capítulo dedicado a las traducciones, p. 170:

Estará permitido traducir dos palabras por una y una por dos; y tratándose de cualquier otro número, cuando ya domines la lengua, aún más: añadir o suprimir algo.

\section{Una obra erasmista}

El carácter erasmista del libro V del Carro de las donas (original del adaptador) fue descubierto por D. Viera, quien lo expresó asíí: «Sin duda, nuestro fraile anónimo conoció el Enchiridion de Erasmo, ya que esta obra influyó mucho en el Lib. V del Carro. La alegoría del caballo (Cap. II a VIII, Lib. V, fols. V, va-XIX, rb) viene del Enchiridion. Es evidente que la influencia erasmista y especialmente del Enchiridion no se limita a esta alegoría, pues el tema del «militis Christi», que se trata extensivamente en el Lib. V del Carro pudo venir de esta obra de Erasmo».

Estoy plenamente de acuerdo con D. Viera en su apreciación del libro V del Carro. Pero de ese hecho hay que sacar la conclusión de que por los años 15391540 la exposición de la doctrina erasmista se compaginaba muy mal con la pertenencia a la orden franciscana, ya que por entonces las obras de Erasmo eran

\footnotetext{
${ }^{6}$ Viera, D., «Un estudio textual del «Carro de las donas»...», p. 170.
} 
perseguidas en España. Por el contrario, el evidente erasmismo del Carro está hablando a favor de Luis Vives, el amigo y seguidor inquebrantable del maestro holandés. En su retiro de Flandes y ya en el final de su vida Vives tenía toda la libertad para exponer la doctrina de su maestro y amigo, aunque considerara conveniente ocultarse bajo el anonimato de un fraile franciscano.

\section{Nuestra España}

En el Carro de las donas tiene una elevada frecuencia la expresión nuestra España, de la que pondremos algunos ejemplos, como en I, 474:

Y vimos en nuestra España que algunas personas...

en I, 497:

En nuestras Hespañas ha havido mugeres, casadas y viudas...

en I, 517:

yo no hize más pesquisa de la que es pública y cognoscida en toda nuestra España

en I, 521:

procuro de nuestro muy santo padre una bulla del sacramento para toda nuestra Hespaña

en II, 108:

Porque vimos que en una ciudad de nuestra Hespaña. 1189:

Tal expresión la encontramos en la obra de Vives Satellitium animae, p.

cosa que vulgarmente se dice en nuestra España, con este adagio: Haz bien y no mires a quien

y muy parecida en De concordia et discordia in humano genere, p. 200:

Mi España, dividida desde sus orígenes en pequeños reinos...

Además el nombre de España es mencionado diecisiete veces en la misma obra De concordia, lo que pone de manifiesto el especial cariño que Vives sentía hacia España, a pesar de lo que había sufrido su familia en ella.

Nota: Las numerosas menciones de España apuntan hacia una persona que escribe fuera de España, ya que el que vive dentro no siente la necesidad de nombrarla con frecuencia. 


\section{CONCLUSIONES}

\section{1. ${ }^{a}$ Ni la horca ni la hoguera}

Hemos visto que el gran Foulché-Delbosc pedía la horca y la hoguera para el traductor del Carro de las donas. Pues bien, ni la una ni la otra son necesarias, porque un autor puede perfectamente aprovecharse de forma anónima de otros escritos suyos. Es lo que quiso hacer una vez más Luis Vives, y sus razones tendría.

\section{2. ${ }^{a}$ Una demostración segura}

La adaptación del Libre de les dones de Eiximenis, así como la composición del libro quinto, fueron hechas con toda seguridad por Vives, ya que en la adaptación se incluyen numerosos textos del humanista valenciano. No puede dudarse, por tanto, de su presencia, corroborada por argumentos que sólo pueden aplicarse a él. Con esta solución todas las piezas del enigmático puzzle del $\mathrm{Ca}$ rro de las donas encajan a la perfección y, en consecuencia, se confirma de forma palmaria la verdad de todos mis trabajos anteriores. Si alguien esperaba la prueba del nueve, ya la tiene.

\section{BIBLIOGRAFÍA}

CALERo, Francisco, Juan Luis Vives, autor del Diálogo de las cosas acaecidas en Roma y del Diálogo de la lengua. Valencia, Ayuntamiento, 2004.

CALERo, Francisco, Juan Luis Vives, autor del Diálogo de Mercurio y Carón. Valencia, Ayuntamiento, 2004.

CALERo, Francisco, Juan Luis Vives, autor del Lazarillo de Tormes. Valencia, Ayuntamiento, 2006.

Clausell NÁcher, Carmen, Carro de las donas. Valladolid, 1542. Adaptación del Llibre de les dones de Francesc Eiximenis O.F.M. realizada por el P. Carmona O.F.M. 2 vols. Madrid, F.U.E. y Universidad Pontificia de Salamanca, 2007. (Las citas se hacen por esta edición).

EIXIMENIS, Francisco, Este deuoto libro se llama carro de las donas, trata de la vida y muerte del hombre christiano. Valladolid, Juan de Villaquiran, 1542.

FERNÁNDEZ AlmUZANA, Eugenio, «Influencia de España en la restauración de la Universidad de Coimbra. Vives y Juan III». Hispania, 1940: 71-82.

Fitzmaurice-Kelly, Julia, «Vives and the Carro de la donas». Revue hispanique, LXXXI (1933): 530-544.

MeSEGUER Fernández, Juan, «El traductor del Carro de las donas, de Francisco Eximenez, familiar y biógrafo de Adriano VI». Hispania, LXXV (1959): 230-250.

MeSEGUER FernÁNDEZ, Juan, «Documentos históricos diversos. I Documentos cisnerianos». Archivo Iberoamericano XXVII (1977): 355-401. 
Moreno Gallego, Valentín, La recepción hispana de Juan Luis Vives. Valencia, Biblioteca Valenciana, 2006.

VÁZQUEZ JANEIRO, Isaac, «En busca de un nombre para el traductor del Carro de las donas de F. Eximénez». Humanismo, Reforma y Teología. Cuaderno 25. Serie Estudios 7. Madrid, 1981.

VIERA, David J., «Más sobre Vives y el Carro de las donas». Estudios franciscanos, LXXV (1974): 145-161.

VIERA, David J., «Un estudio textual del Carro de las donas, adaptación del Llibre de les dones». Estudios franciscanos, LXXVII (1976): 153-180.

VIVES, Juan Luis, De concordia et discordia in humano genere. De pacificatione. Quam misera esset vita christianorum sub Turca. Sobre la concordia y la discordia en el genero humano. Sobre la pacificación. Cuán desgraciada sería la vida de los cristianos bajo los turcos. Trad. de Francisco Calero, M. ${ }^{\text {a }}$ Luisa Arribas y Pilar Usábel. Valencia, Ayuntamiento, 1997.

ViVES, Juan Luis, De Europae dissidiis et republica. Sobre las disensiones de Europa y sobre el Estado. Traducción de Francisco Calero y M. ${ }^{a}$ José Echarte. Valencia, Ayuntamiento, 1992. En este volumen incluyó Vives los siguientes opúsculos: Sobre las perturbaciones de Europa al Papa Adriano VI, Sobre la captura del Rey de Francia a Enrique VIII, Rey de Inglaterra, Sobre el gobierno del reino, Sobre la guerra y la paz a Enrique VIII, Sobre las disensiones de Europa y la guerra de los turcos (Diálogo de los turcos).

VIVES, Juan Luis, De institutione feminae christianae. La formación de la mujer cristiana. Traducción de Joaquín Beltrán. Valencia, Ayuntamiento, 1994.

ViVEs, Juan Luis, De ratione dicendi. Del arte de hablar. Introducción, edición y traducción de José Manuel Rodríguez Peregrina, Granada, Universidad de Granada, 2000.

VIVES, Juan Luis, De subventione pauperum sive de humanis necessitatibus. Sobre el socorro de los pobres o sobre las necesidades humanas. Trad. de Francisco Calero. Valencia, Ayuntamiento, 2004.

VIVES, Juan Luis, Epistolario. Traducción de José Jiménez Delgado. Madrid, Editora Nacional, 1978.

Vives, Juan Luis, Satellitium animae. Escolta del alma. Traducción de Lorenzo Riber, Obras completas de Vives, I. Madrid, Aguilar, 1947. 